\title{
LARGE SCALE EXPERIMENTAL STUDY ON THE FIRE HAZARD OF BUILDINGS' U-SHAPE FAÇADE WALL GEOMETRY
}

\author{
Weigang YAN ${ }^{\mathrm{a}}$, Lin JIANG ${ }^{\mathrm{b}}$, Weiguang $\mathrm{AN}^{\mathrm{c}}$, Yang ZHOU ${ }^{\mathrm{d}}$, Jinhua $\mathrm{SUN}^{\mathrm{b}}$ \\ ${ }^{a}$ School of Energy and Power Engineering, University of Shanghai for Science and Technology, Shanghai, PR China \\ ${ }^{b}$ State Key Laboratory of Fire Science, University of Science and Technology of China, Hefei, PR China \\ ${ }^{c}$ China University of Mining and Technology, 221116 Xuzhou, PR China \\ ${ }^{d}$ Department of fire protection Engineering, School of civil engineering, Central South University, \\ 410075 Changsha, PR China
}

Received 12 Nov 2015; accepted 18 Jan 2016

\begin{abstract}
Buildings have U-shape façade designs for certain purposes such as lighting. However, such designs may lead to a higher fire hazard. In this paper, large scale experiments of upward flame spread over XPS insulation material were conducted to investigate the fire hazard of building's U-shape façade wall geometry. Comparison to previous laboratory scale experiments were also presented. Theoretical analysis was performed to reveal the mechanism of the U-shape geometry's influences. It is found that such geometry design would increase the fire hazard of buildings: flame spread rate and flame height increased with U-shape's geometrical factor. The results agreed with theoretical analysis. It is expected that the buildings' U-shape façade wall geometry would greatly benefit flame spread for full scale applications and increase the fire hazard. Thus engineers should be careful with such façade wall designs, especially for residential building designs.
\end{abstract}

Keywords: U-shape geometry, flame spread, sidewall effect, XPS, façade wall design.

\section{Introduction}

As the demand for energy saving buildings increases rapidly worldwide, passive thermal insulation coatings is one of the key approach to meet the buildings energy efficiency requests (Papadopoulos 2005). Nowadays, many kinds of insulation materials are used or under development to provide excellent thermal insulation properties. Some state-of-the-art technology could even provide 10 times better insulation performance than traditional ones (Jelle 2011). Those state-of-the-art materials have amazing performance. Due to the cost, manufacturing or other problems, those materials yet have not been widely used in constructions. The traditional materials such as polystyrene foams and polyurethane foam, however, have been widely accepted and used in many countries (especially in developing countries such as China) for the cost efficiency concerns. They have also been widely accepted in old buildings' cost effective retrofitting projects (Ruzgys et al. 2014; Carlos, Corvacho 2010). However, they have a severe safety problem that those foams have high fire hazards. The foams are highly flammable and will release large amount of toxic gas during combustion. In this case, to evaluate and control the fire hazard is very important for the buildings using foams as insulation material.
Not only insulation materials would have high fire hazard, but both Chow's (2011) and Ji's et al. (2016) works showed that the façade wall design would influence buildings' fire hazard. More importantly, buildings' U-shape façade wall geometry (shown in Fig. 1) could greatly influence the buildings' fire hazard. The internet photos of Al Tayer blaze in Sharjah, UAE, 2012 and high-rise apartment building fire in Grozny, Russia, 2013, regardless that resolutions were low and photos were not clear, implied that the buildings' facade wall could have influences on fire spread. Another fire case of Shenhuacheng Fire, Urumqi, China, Sept. 2010 would show a clear view of such influences as shown in Figure 1. Because the U-shape designs are most commonly adopted in residential building façade wall designs, it is much more important to study the influence of such wall designs.

In recent years, much attention has been drawn on the fire hazard of building insulation materials itself. Stec and Hull (2011) studied the fire toxicity of several insulation materials for both well-ventilated and under-ventilated conditions. The results showed that the toxicity of polystyrene and polyurethane foams were greater than glass wool and stone wool but smaller than polyisocya-

Corresponding author: Jinhua Sun

E-mail:sunjh@ustc.edu.cn 

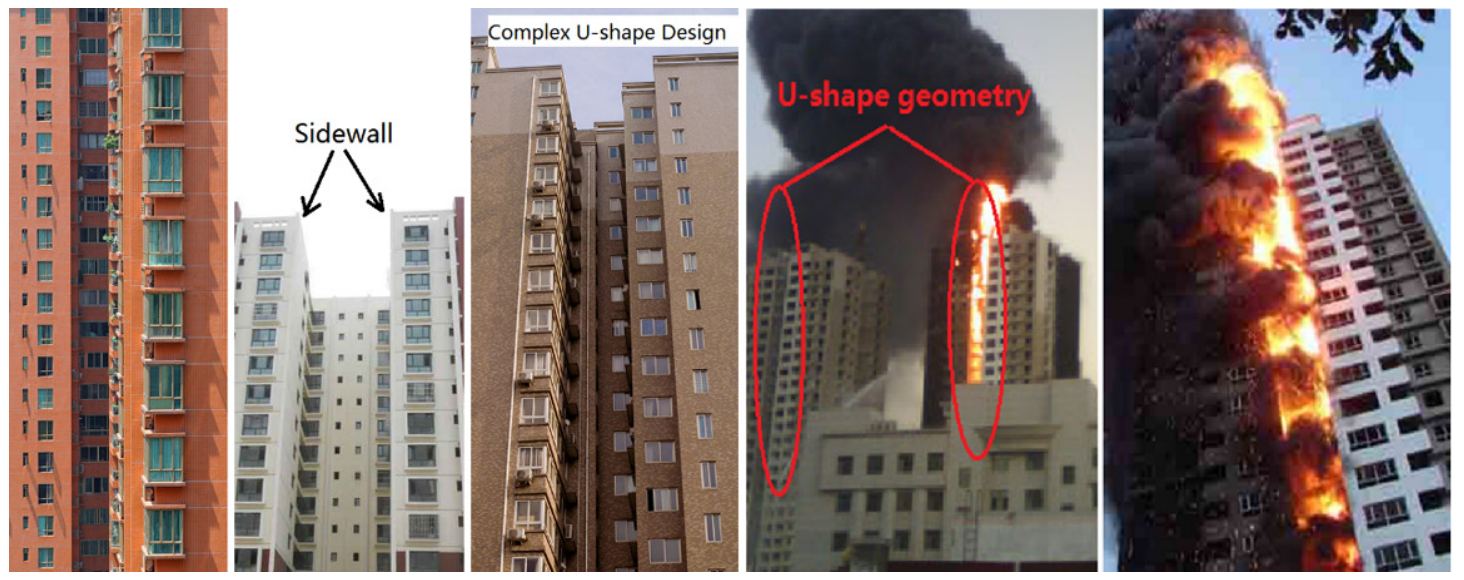

Fig. 1. Different U-shape façade wall geometry (From left: 1-3) and a fire case of such geometry (From right: 1-2. Shenhuacheng Fire, Urumqi, China, Sept. 2010)

nurate. Zhang et al. $(2011,2013)$ conducted experiments on the characteristics of horizontal flame spread over extruded polystyrene (XPS) surface on both plain and plateau. It was found that the heat transfer mechanism had changed with different sample widths: the flame spread was controlled by convection transfer regime initially while gradually changed to radiation regime as the sample width increased. Huang et al. $(2011,2012)$ and Jiang et al. $(2013,2014)$ investigated the different combustion behaviors of XPS and expanded polystyrene (EPS). Qualitative observations of some thermal properties with some theoretical analysis were provided. For the fire hazard of buildings' U-shape façade wall geometry, little efforts have been devoted to this topic. Tsai $(2007,2009,2011)$ investigated the sidewall effect on upward flame spread, which is similar to U-shape geometry but the geometrical factor is very small. It was found that when sidewall was present, the flame spread rate was larger than that without sidewalls. A hypothesis was also proposed. An et al. (2014) investigated the sidewalls, dimension and pressure influences on downward flame spread on plateau using XPS as test material. The duration of melting stage without sidewalls was found to be longer than that with sidewalls. A model was also provided. Good agreement was found between the model and experiment results. However, even though those works contained part of U-shape façade wall geometry, the influence of U-shape geometry was not well discussed. In our recent works, Yan et al. (2015a, 2015b) focused on the U-shape geometry's influences on the characteristic of vertical flame spread under various environment. It was found that U-shape geometry would benefit flame spread and thus increase fire hazard. Pseudo chimney effect hypothesis was provided and theoretical analysis was performed to reveal the mechanism of U-shape geometry's influences. The analysis agrees with laboratory scale experiment result. As a work in progress, large scale experiments were conducted to check the applicability of the conclusions of laboratory scale experiments and evaluate the previously provided hypothesis.

\section{Experimental apparatus}

To investigate the fire risks of the U-shape geometry of the building's façade wall covered with insulation materials, large scale upward flame spread experiments using extruded polystyrene (XPS) foams with different U-shape configurations were conducted on our large scale building fire facility. Figure 2 shows the schematic diagram.

The facility basically consists of a flat back wall, a set of sidewalls with different sizes and DAQ devices including digital camera, electronic balance. The back wall used $8 \mathrm{~cm}$ thick fire-retardant calcium silicate board which has good insulation property to hold and support sample and sidewalls. Each piece of sidewalls was $1 \mathrm{~cm}$ thick gypsum board with corresponding size that attached to steel frame. Those sidewalls were in pairs that could be hinged to the calcium silicate board back wall. The DAQ devices include a commercial HD camera and an electronic balance. The camera was mounted in front of the facility that could record the experiments' video for

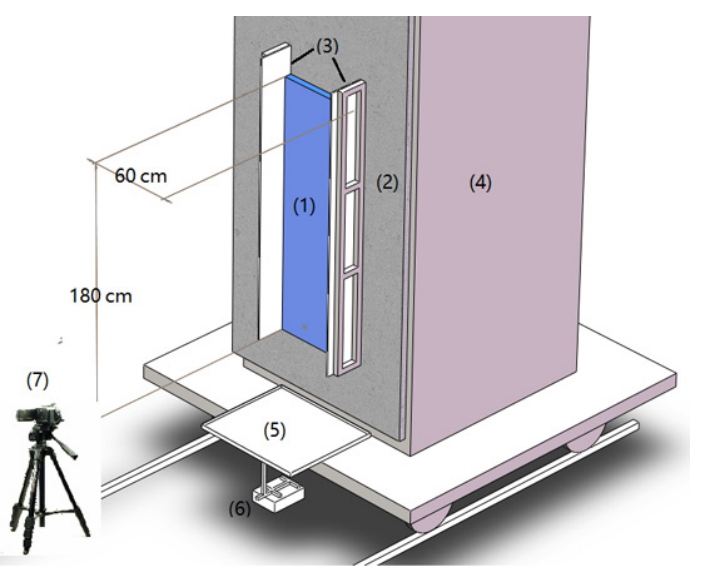

Fig. 2. Schematic diagram of experimental apparatus: (1) XPS foam slab, $60 \mathrm{~cm}$ wide, $180 \mathrm{~cm}$ high and $5 \mathrm{~cm}$ thick; (2) Calcium silicate board; (3) Sidewalls with steel frame, various widths; (4) Back bone facility; (5) Aluminum foil pan; (6) Electronic balance; (7) Camera 
Front View

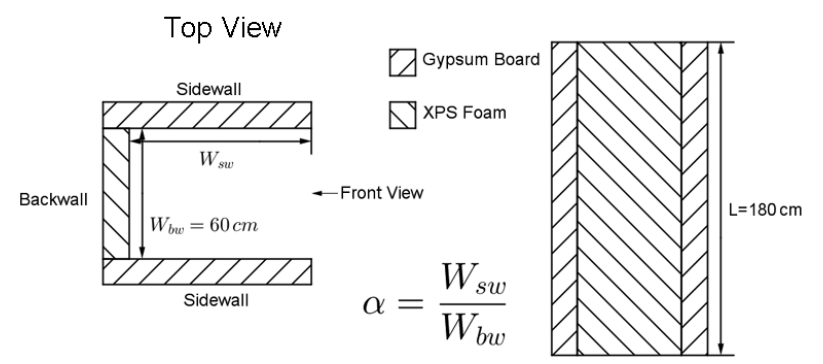

Fig. 3. Illustration of definition of geometrical factor

further analysis. The balance was placed under the foams. A pan made of aluminum foil was place on the balance to collect the droplets from the foams. Proper support and insulation measures were taken to protect the balance from damage. The range and precision of the balance are $8 \mathrm{~kg}$ and $0.01 \mathrm{~g}$, respectively.

To have a better understanding of U-shape geometry's influences on upward flame spread, a dimensionless geometrical factor is used in this work as: $\alpha=w_{\text {sidewall }} / w_{\text {backwall }}$, where $w_{\text {sidewall }}$ and $w_{\text {backwall }}$ are the inner widths of sidewall and back wall of Ushape geometry, shown in Figure 3. In our experiments, the width of back wall was $60 \mathrm{~cm}$. And the width of sidewalls were $0,20,40,60$ and $80 \mathrm{~cm}$, giving the geometrical factor $\alpha$ a variation of $0,0.33,0.67,1.0$ and 1.33.

The XPS foams used in our experiments were non-flame-retardant foams with a size of $60 \times 180 \times 5$ (Width $\times$ Height $\times$ Thickness, unit: $\mathrm{cm}$ ). The density of the foam in the experiments was $30 \mathrm{~kg} / \mathrm{m}^{3}$. Only the back wall was covered by the foam.

The burner in our experiments was an in-house line burner. The burner was a $150 \mathrm{~cm}$ long, $4 \mathrm{~cm}$ wide and $4 \mathrm{~cm}$ deep pool using $\mathrm{n}$-Heptane as its fuel. The burner was placed right under and $1 \mathrm{~cm}$ from the bottom of the foam slab. Once ignited, the burner was instantly removed. Each configuration was performed 3 times.

\section{Results and discussions}

\subsection{Flame front spread}

The information on flame front could be extracted from video record by processing frames in an experiment. In this work, to avoid the high frequency fluctuations of flame during the combustion, arithmetic per pixel average of 10 sequential frames $(0.2 \mathrm{~s}$ interval for 10 sequential frames as the video is 50 frames per second) was performed in the preprocessing stage. The flame data were extracted for further analysis every $0.6 \mathrm{~s}$. The flame data were obtained through an extended OTSU method (Yan et al. 2012). During the whole video processing, the region of interest (ROI, i.e. flame spread region) was divided into 6 vertical sub-ROIs, the flame spread information was processed within each individual sub-ROI. This strategy was chosen because the flame front of large scale experiments might not form a perfect horizontal line due to environmental interruptions: in some experiments, the stable flame front lines were in '^' shape, ' $\mathrm{v}$ ' shape or other shapes, which means, the overall information is insufficient. Since the camera was placed in front of the foam and the ROI was in the center and only a small part of the view, the camera distortion of the image could be ignored so that the pixel distance could be regarded as uniform. The real distance between different pixels could be then calculated.

Figure 4 shows the 20 points smoothed average flame front position of each condition as a function of time. It should be explained that the time $t=0 \mathrm{~s}$ denotes the time when the burner was removed as the bottom of the foam was ignited. At that moment, the flame front position is defined as 0 . In fact, the real flame front position to the bottom of the foam was around $200 \mathrm{~mm}$ which was the average flame height after ignition. The figure shows that, for each condition, the flame front had an acceleration trend when the flame front position was much lower than about $1200 \mathrm{~mm}$. However, when the flame front reached about $1200 \mathrm{~mm}$, the acceleration trend was not obvious. The reason for this was that after ignition, the flame started to spread upward, which was an acceleration process: the heat feedback to the preheat zone was strong and the pyrolysis front spread fast. Although the bottom part of the pyrolysis zone would melt and drop due to the XPS foam property, which resulted in the decrease of pyrolysis zone area and consequently the heat release rate. The heat loss through the molten part was relatively small at the beginning, which could be proved later by mass data. Thus the flame spread accelerated after ignition, i.e., the flame front position was in acceleration trend. However, as the pyrolysis zone area increased, the amount of molten foam in pyrolysis zone accumulated rapidly, which led to the fast dropping of the molten fuel. Moreover, some part of the solid foam in the pyrolysis zone would be burnt through so that the bottom part of those burnt through area would drop even with

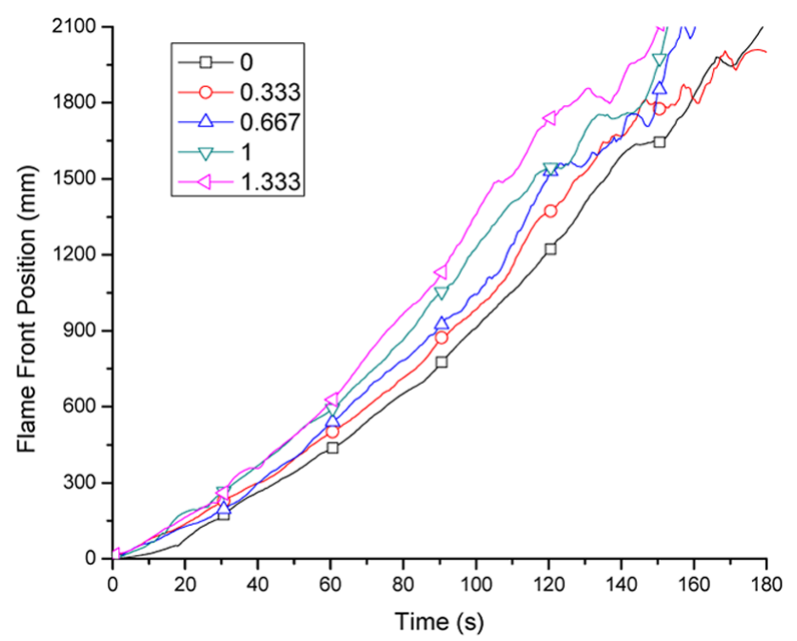

Fig. 4. 20 points smoothed average flame front position of each condition as a function of time (The symbols on each curve are only for visual identification purposes) 
un-molten part. This would decrease the heat release rate. The upward flame spread and the dropping fuel were in competitive relationship. As the flame spread, the two effects would reach a balance point. This is the reason that acceleration trend was not obvious when the flame front approached $1200 \mathrm{~mm}$. When flame front was higher than $1600 \mathrm{~mm}$, which meant that the flame front reached the top of the foam, the flame front position started to fluctuate and decelerate, this could be due to that the foam's top edge was $50 \mathrm{~mm}$ to the back wall and would lead to turbulence which fluctuate the flame. Moreover, the pyrolysis zone at that moment was about to reach the top of the foam and the flame would stop spread and gradually extinguish. Thus the flame front was decelerating.

For different configurations, it could be found from Figure 4 that the flame spread faster with a greater geometrical factor. The reasons for this are as follows.

First, during the propagation, flame had to entrain air for combustion. Without sidewalls, flame could entrain air from front, side and bottom. However, when sidewalls were added, the air entrainment from side was suppressed, indicating that more air was entrained from front and bottom. When more air entrained from side and bottom, the air flow speed from side and bottom would increase. The increased air flow speed from bottom would benefit the upward flame spread. Also, the sidewalls and back wall would confine the flame and hot smoke to the virgin foam surface. Then the heat feedback to the foam surface became stronger, resulting in a faster flame spread. Moreover, the air flow from bottom lengthened the flame height which directly increased preheat zone length. The sidewall and back wall also formed a channel which could guide the flame and hot smoke adhere to the foam surface. This would also benefit flame spread.

Second, the sidewalls changed the heat transfer between flame and surrounding environment. Without sidewalls, the flame directly radiates to ambient environment. Flame also directly loses heat through convective heat transfer. When sidewalls were present, the sidewalls added heat resistance to the convective heat transfer between flame and both sides. Sidewalls also blocked the radiation from two sides and reflected part of the radiation back to the foam. Moreover, the sidewall would be heated during the flame propagation. The flame radiation received by hot sidewalls would be less than that received by surrounding environment in the situation that without sidewalls.

Both effects were affected by the sidewall width. When sidewall width increased, the confinement effect of entrainment and the enhancement effect of heat feedback would increase. Thus the flame spread speed increased with geometrical factor.

\subsection{Flame height}

Flame height data were also obtained using previous method. Figure 5 shows the 20 points smoothed average flame height of each condition as a function of time.

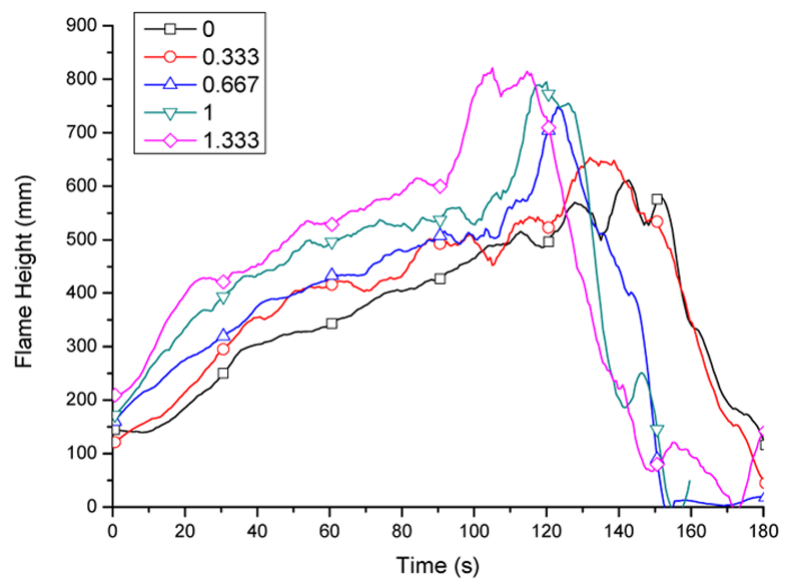

Fig. 5. 20 points smoothed average flame height of each condition as a function of time (The symbols on each curve are only for visual identification purposes)

It could be found that the developing of flame height as a function of time for each condition went through 4 stages. The first stage was the initial stage right after ignition. In this stage, the flame was relatively weak so that the pyrolysis zone area and heat release rate were small. As the flame spread, the flame height grew quickly. The second stage was a slower growth stage compared to the first stage. In this stage, large amount of the molten fuel and part of the solid foam started to drop. This would slow the flame spread speed and also the pyrolysis speed. Then the flame height increase speed was slowed. The flame height in the third stage had a sharp increase. During this stage, probably limited by the air entrainment, the flame was lengthened for the pyrolyzate to combust. The flame height in configuration of geometrical factor 1.33 also implied that there might be a steady stage in which the flame height would be constant if the foam were long enough. This could be reasonable because the flame spread would become steady given enough time. After the third stage, the flame height decreased rapidly as in this stage the flame had reached the top of the foam and started to extinguish.

For different configurations, it could be found that the flame height was higher with a greater geometrical factor. With a greater geometrical factor, the induced flow speed from bottom was faster. The effect of confinement on air entrainment was stronger. The heat feedback to the pyrolysis zone was enhanced and more pyrolyzate was released. Thus the flame height was greater. Also, the start time of each stage was shorter as geometrical factor increased. The reason for this could be that the flame spread faster with a larger geometrical factor.

\subsection{Flame spread time}

In most cases, although it could achieve steady state in theory given enough time and distance, the upward flame spread is an unsteady process at the beginning. Thus the time needed for flame to spread over a certain distance is 


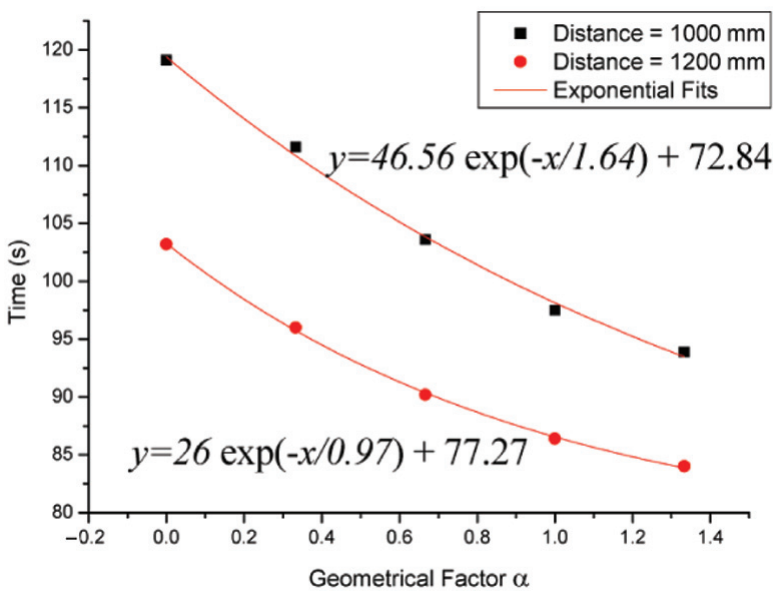

Fig. 6. Time needed for flame to propagate certain distances as a function of geometrical factor (The detailed fitting info is listed in Table 1)

an important factor during upward flame spread. Because it could be used to evaluate and predict flame spread in real scenario. Figure 6 the needed time for different distances as a function of geometrical factor.

It could be found that the needed time decreased with a larger geometrical factor. This could be explained as the flame spread speed was higher with a larger geometrical factor so that the time needed for a certain distance was shorter. Moreover, the needed time and geometrical factor could be estimated using exponential functions. The exponential fitting has two limits: the intercept and the lower boundary. The intercept indicates the corresponding time for flat shape, which in this work was already obtained. However, for those situations in which the flat shape are not tested, the needed time could be estimated using fitting functions. Similar to flat shape, the needed time for a geometrical factor larger than 1.33 could be estimated. The lower boundary represents the time when geometrical factor approaches infinity. When geometrical factor is large enough, $\alpha=3$ for example, the estimated time is close to the lower boundary, implying that the U-shape geometry's pseudo chimney effect has almost reached its largest efficiency. Moreover, the fitting data implied that the flame spread speed would be greatly increased as the needed time was about $30 \%$ to $50 \%$ less for a larger geometrical factor than a flat shape.

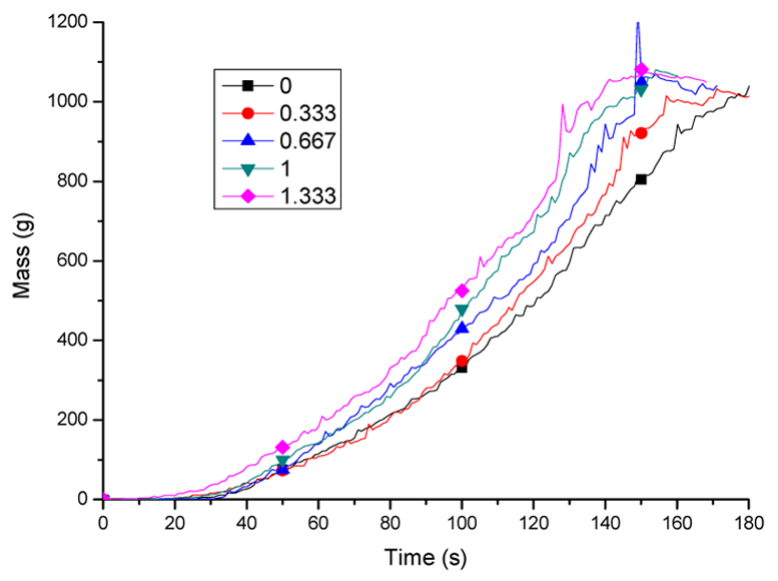

Fig. 7. Average mass accumulation for each configuration as a function of time (The symbols on each curve are only for visual identification purposes)

\subsection{Mass accumulation}

The droplets were collected using pan made of aluminum foil and the mass data were measured during the experiments. The mass data were synchronized with video record manually by starting recording at the same time. Figure 7 shows the average mass accumulation data for each configuration as a function of time.

It could be found that for each configuration, the mass accumulation was accelerating. However, at the very beginning, the mass accumulation remained approximately $0 \mathrm{~g}$. Since at the beginning, the flame was weak. The amount of molten foam was small. Very little amount of droplets dropped. Thus the mass accumulation on balance remained approximately $0 \mathrm{~g}$. As the flame propagated, the pyrolysis zone increased, which led to more molten foam flowing downward and dropping. Then the mass accumulation accelerated. For different configurations, the mass accumulated faster with a greater geometrical factor. This could be explained by that the flame propagated faster and heat release rate was larger.

For a certain experiment (geometrical factor $\alpha=0$ ), Figure 8 shows the mass accumulation data, its first order derivative and the 50 points smoothed curve of the derivative as an example. The derivative curve clearly showed the acceleration of mass accumulation before about $140 \mathrm{~s}$. However, after that, the mass accumulation

Table 1. Detailed fitting information for Figure $6\left(y=A \exp (-x / t)+y_{0}\right)$

\begin{tabular}{llllll}
\hline \multicolumn{2}{c}{ Fitting For distance $=1200 \mathrm{~mm}$} & \multicolumn{3}{c}{ Fitting For distance $=1000 \mathrm{~mm}$} \\
\hline Reduced Chi-Sqr & 0.64972 & & Reduced Chi-Sqr & 0.07418 \\
Adj. R-Sqr & 0.99387 & & Adj. R-Sqr & 0.99876 \\
\hline & Value & SE & & Value & SE \\
\hline $\mathrm{y}_{0}$ & 72.838 & 10.7059 & $y_{0}$ & 77.274 & 1.33261 \\
$\mathrm{~A}$ & 46.562 & 10.3886 & $A$ & 26.014 & 1.26198 \\
$\mathrm{t}$ & 1.6393 & 0.55067 & $t$ & 0.97057 & 0.09118 \\
\hline
\end{tabular}




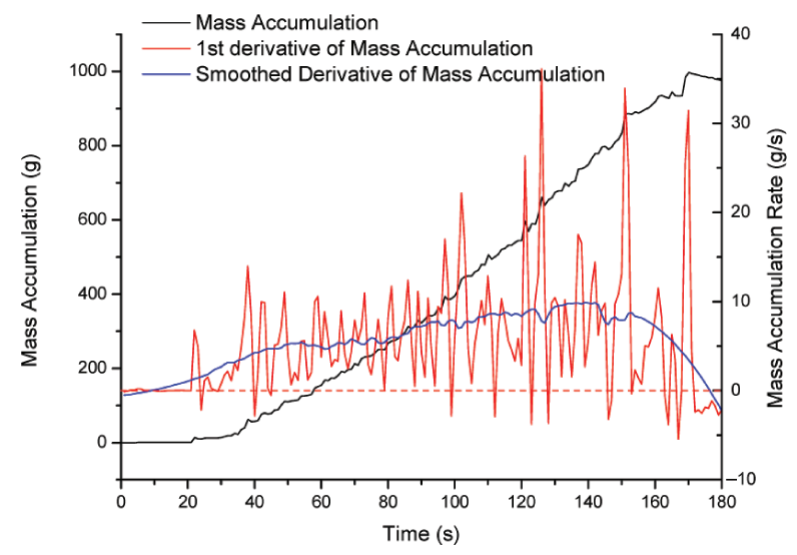

Fig. 8. Mass accumulation, its first order derivative and the 50 points smoothed curve as a function of time for geometrical factor $\alpha=0$ configuration

started to decelerate. When compared to previous flame front and flame height data, the flame started to extinguish after $140 \mathrm{~s}$, this was the reason for the decelerating. During the whole experiment, the droplets were in different sizes and weights. When falling, due to the limit of electronic balance precision, small droplets were not recognizable on the curve, they contributed to a continuously accumulation. However, the bigger droplets (and some fragments of un-molten foam) could be recognized. Since the momentum of those big droplets would give an impulsion on the balance readings, thus formed the sharp peaks of derivative curve.

Since the large droplets contained more fuel and thus would release more heat, which was more hazardous than small ones. The characteristics of those droplets are important. Figure 9 shows the statistical data of recognizable droplets under different configurations. The bar graph demonstrates the overall frequency count of first order derivation peaks for 3 configurations (geometrical factor $0,0.667$ and 1.333), with the $\mathrm{x}$ axis represents the peak intensity of the derivation. That is, for a certain configuration, all the peaks of different experiments were examined and counted according to their peak intensities. The inner graph showed the total number of peaks in each experiment. It could be found that although flame spread speed, flame height and mass accumulation were different for each configuration, the statistical results of large droplets remained homogeneous. The numbers of large droplets were almost constant in different experiments. This indicated that the number of large droplets during combustion was related to foam shape and property, and was irrelevant to geometrical factor. The geometrical factor would affect the flame propagation. However, the droplets were influenced by the fluid accumulation and its properties. When the flame spread speed was high, the molten foam accumulated fast, which would lead to a faster drop. But in this case, the time of the whole propagation decreased since the foam height in each configuration was the same. Moreover, the frequency count of those droplets showed that droplets within a certain range

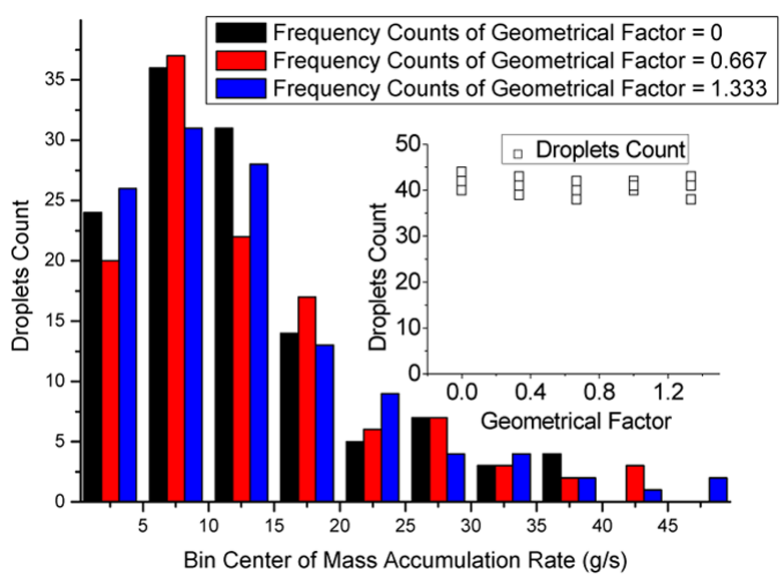

Fig. 9. Statistical results of recognizable droplets under different configurations

of sizes were more likely to form and drop from the preheat zone, regardless of geometrical factor. For Figure 8, droplets were more frequently fell into the second category (which had the peak value of mass accumulation rate between $5 \mathrm{~g} / \mathrm{s}$ and $10 \mathrm{~g} / \mathrm{s}$ ).

\subsection{Comparison to previous works of U-shape's influences}

Laboratory scale experiments have been conducted to investigate the U-shape sidewall effect on both upward and downward flame spread (Yan et al. 2015a, 2015b). In those works, different materials and configurations were tested, theoretical analysis were also presented.

One of our previous works (Marked as WORK 1) focused on the laboratory scale upward flame spread along building's U-shaped façade geometry over insulation material on plain (Hefei) and plateau (Lhasa) (Yan et al. 2015a). In that work, the insulation material used was non-flame-retardant rigid polyurethane (PU) foam, while both back wall and sidewall was covered by PU foam. The geometrical factors were from 0.4 to 1.6 with a step of 0.2 .

Although those two works have used different materials, sample sizes and geometrical factor configurations, even different sidewalls' types. The similarity between the basic geometrical structures of the two experiments had led to highly similar results. In both works, the flame front positions were obtained and analyzed. Figure 10 shows the comparison of the two experimental results. Note that the flame front position started from the bottom of the U-shape geometry. In WORK 1 and this work, the flame front both accelerated during experiments. This was because during the experiments, the flame spread speed was accelerating and the pyrolysis zone was increasing, regardless of the materials. The flame spread would eventually reach a steady state, since fuel in the bottom part of the pyrolysis zone are limited and would burnout. However, the time when the flame spread reaches steady state will depend on the material's properties and experiment scale. In WORK 1, it could be found that flame 


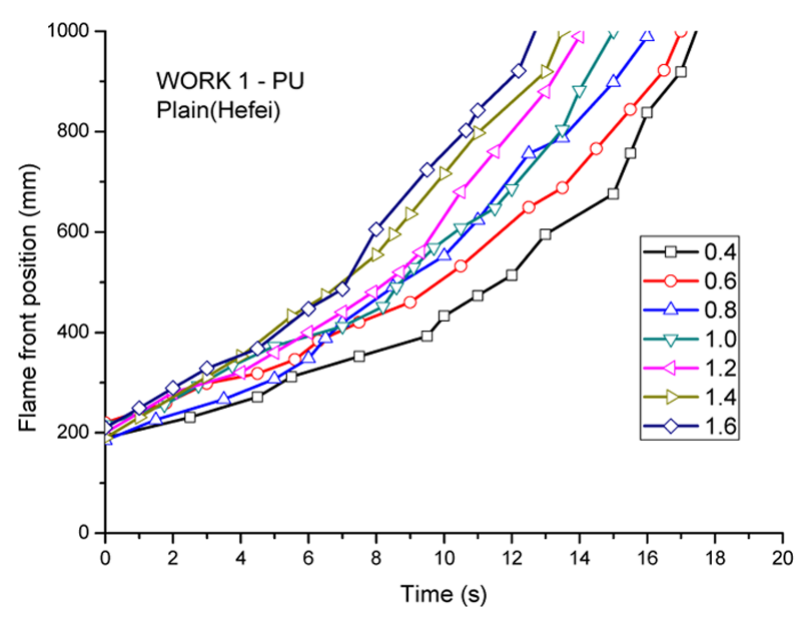

Fig. 10. Flame front position results from WORK 1

front spread faster with a greater geometrical factor on both plain and plateau. The results were very similar to that in this work, regardless of the sidewalls' material in WORK 1 was combustible PU foam and that in this work was non-combustible gypsum board. This could be explained by the pseudo chimney effect proposed in WORK 1. A brief analysis based on pseudo chimney effect was provided in this work as follows.

For both WORK 1 and this work, assuming that the preheat zone length equals to flame tip length and heat flux in preheat zone is constant, the upward flame spread speed for thermally thick material could be written as (Quintiere 2006):

$$
v_{f, \text { thick }}=\frac{\mathrm{d} y_{p}}{\mathrm{~d} t}=\frac{4\left(\dot{q}_{f}^{\prime \prime}\right)^{2}\left(y_{f}-y_{p}\right)}{\pi\left(k \rho c_{p}\right)\left(T_{i g}-T_{s}\right)}=\frac{y_{f}-y_{p}}{t_{i g}},
$$

where: $\dot{q}_{f}^{\prime \prime}$ is the heat flux received by preheat zone; $y$ denotes the vertical distance, while subscripts $f$ and $p$ refer to flame front and pyrolysis front; $k, \rho$ and $c_{p}$ are the material's conductivity, density, and specific heat, respectively. $T_{i g}$ and $T_{s}$ are ignition temperature and ambient temperature, respectively; $t_{i g}$ is ignition time which could be regarded as a function of feedback heat flux and material's properties. The flame front position is related to pyrolysis front position (Quintiere 2001): $y_{f}=C_{f} y_{p}$. That is, the flame spread speed could be estimated by flame front position.

Without sidewalls, the flame could entrain air from front, side and bottom, as shown in Figure 11. Flame and hot smoke could expand to both sides and leave the pyrolysis zone and preheat zone, which decreases the heat feedback. However, with sidewalls, the air entrainment from two sides are suppressed, flame and hot smoke are limited within the pyrolysis zone and preheat zone, increasing the heat feedback. Moreover, when the air entrainment from two sides are suppressed, considering the total amount of air need for combustion should remain the same, more air has to be entrained from front and bottom. This would induce (or at least enhance) two flows: the upward flow from bottom and the horizontal flow from front. The upward flow would lengthen the flame. Since it has an initial speed compared before accelerated by buoyancy. The horizontal flow would force the flame and hot smoke adhere to the fuel surface. This would increase the heat feedback to the virgin fuel. As the geometrical factor increases, which means that the sidewalls' length increases and the U-shape geometry grows deeper, it is more difficult to entrain air from side and front. The reason for this could be explained by that the increasing sidewalls length would greatly block the side entrainment, and the sidewalls would introduce stronger friction force as the sidewalls become longer. As a compensation to the restrained side and front entrainment, more air has to be entrained from bottom to maintain combustion. In this case, the flame height would increase with geometrical factor in the situations which have the same pyrolysis zone length. The flame height data in Figure 5, to some extent, proved the analysis since the overall trend of flame height in each configuration increased with geometrical factor. Thus, the flame spread speed in both WORK 1 and this work increased with geometrical factor.

Another previous laboratory scale work (Marked as WORK 2) investigated the downward flame spread with sidewalls under different ambient pressures which tried to reveal the mechanisms of the sidewall effect (Yan et al. 2015b). The results from WORK 2 could be utilized to explain the results for upward cases. With the assumption that: 1. The flame would entrain air from front, side and bottom in a uniform manner; 2 . The sidewalls would block part of the side entrainment; 3 . The total amount of air for combustion would remain the same. More air has to be entrained from front and bottom, shown in Figure 11. Similar to the downward case, the induced air flow speed for upward flame spread would be:

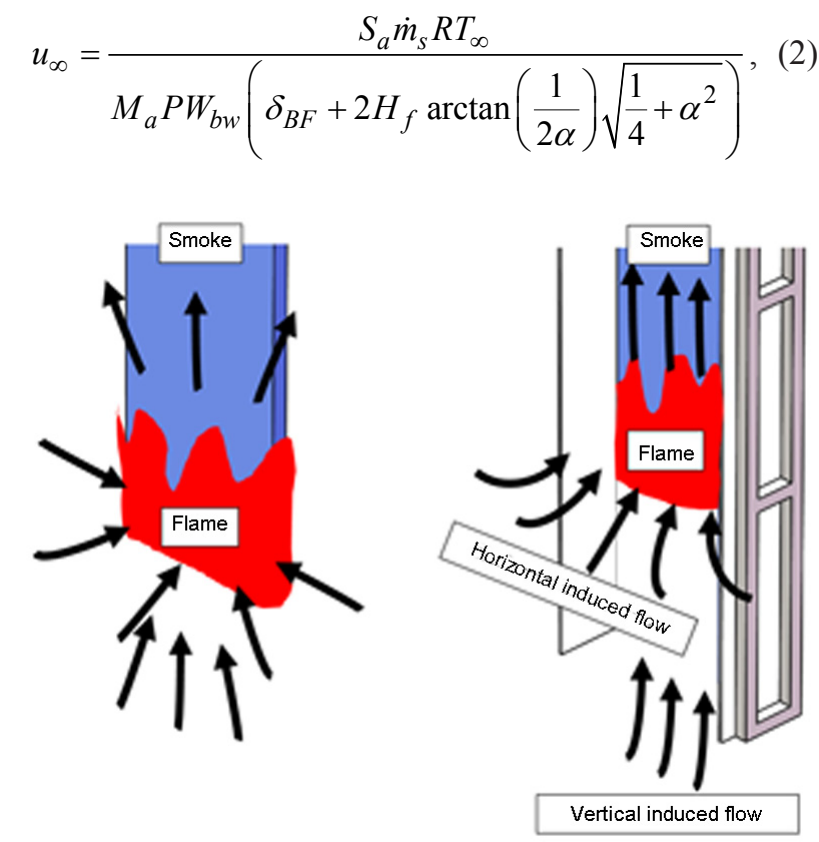

Fig. 11. Illustration of air entrainment mechanism of downward flame spread with (right) and without (left) sidewalls 
where $S_{a}$ denotes the stoichiometric air-to-fuel mass ratio; $\dot{m}_{s}$ means mass loss rate of fuel; $R, T_{\infty}, M_{a}$ and $P$ are ideal gas constant, ambient temperature, average air mole mass and pressure, respectively. $W_{b w}$ is the back wall width. $\delta_{B F}$ and $H_{f}$ are flame thickness and flame height, respectively. Note that the flame is treated as a cuboid with a dimension of $W_{b w} \times \delta_{B F} \times H_{F}$. Moreover, $\dot{Q}_{a, t o t a l} \approx S_{a} \dot{m}_{s} R T_{\infty} /\left(M_{a} P\right)$ is the volume of entrained air. The rest part $A_{e}=W_{b w}\left(\delta_{B F}+2 H_{f} \arctan \left(\frac{1}{2 \alpha}\right) \sqrt{\frac{1}{4}+\alpha^{2}}\right) \quad$ is the equivalent air entrainment area. More details should refer to WORK 2. For this work, the back wall width was constant. The flame height could be regarded as constant during semi-steady state as shown in Figure 5. The flame thickness was mainly determined by reaction rate and mass transfer. It could be found that the induced air speed would increase with geometrical factor $\alpha$. This is consistent with previous analysis. Moreover, it could be proved that the induced flow speed has an upper limit, thus implied that the pseudo chimney effect would eventually reach a limit as geometrical factor increases.

Although different materials and configurations were used, the experiment results showed that the sidewall effect would apply to a wide range of scales and the influence of sidewall would benefit the flame spread.

\section{Conclusions}

In this paper, large scale experiments of upward flame spread over XPS were conducted to investigate the fire hazard of building's U-shape geometry of façade wall. The results were analyzed to reveal the mechanism of the sidewall effect. The conclusions are summarized as follows:

1. The overall flame spread speed increased with geometrical factor.

2. The time needed to spread a certain distance decreased exponentially with geometrical factor. The upper and lower boundary indicates the case of flat shape and the case when sidewall length approaches infinity. This could be used to evaluate the fire hazard of U-shape design.

3. The overall flame height was higher with a greater geometrical factor at the same time. The largest flame height, however, increased slightly with geometrical factor.

4. The droplets' mass accumulated faster as geometrical factor increased. While the statistical results of droplets number and mass distribution for different configurations were identical.

Comparison to previous laboratory scale experiments was also presented. It is found that the results from those works were in the same trend regardless the tested materials and configurations. The mechanism of the sidewall effect could be explained by pseudo chimney effect and the corresponding analysis.
With regard to current progress, it is expected that the buildings' U-shape façade wall geometry would greatly benefit flame spread for full scale applications. Thus would increase the fire hazard of such buildings. Engineers should be more careful with such façade wall design, especially for residential building designs. Also, attention should be drawn upon medium scale applications such as atrium design.

\section{Acknowledgements}

This work was supported by the National Natural Science Foundation of China (NO. 51578524), the National Natural Science Foundation of China (NO. 51323010), the Fundamental Research Funds for the Central Universities (NO. WK2320000036), and the open fund of State Key Laboratory of Fire Science (NO. HZ2017-KF07).

\section{References}

An, W.; Wang, Z.; Xiao, H.; Sun, J.; Liew, K. M. 2014. Thermal and fire risk analysis of typical insulation material in a high elevation area: Influence of sidewalls, dimension and pressure, Energy Conversion and Management 88: 516-524. https://doi.org/10.1016/j.enconman.2014.08.026

Carlos, J. S.; Corvacho, H. 2010. Retrofit measures in old elementary school buildings towards energy efficiency, Journal of Civil Engineering and Management 16(4): 567-576. https://doi.org/10.3846/jcem.2010.63

Chow, C. L. 2011. Numerical studies on smoke spread in the cavity of a double-skin façade, Journal of Civil Engineering and Management 17(3): 371-392. https://doi.org/10.3846/13923730.2011.595075

Huang, X.; Sun, J.; Ji, J.; Zhang, Y.; Wang, Q.; Zhang, Y. 2011. Flame spread over the surface of thermal insulation materials in different environments, Chinese Science Bulletin 56: 1617-1622. https://doi.org/10.1007/s11434-0104187-z

Huang, X. J.; Wang, Q. S.; Zhang, Y.; Yin, Y.; Sun, J. H. 2012. Thickness effect on flame spread characteristics of expanded polystyrene in different environments, Journal of Thermoplastic Composite Materials 25(4): 427-438. https://doi.org/10.1177/0892705711411341

Jelle, B. P. 2011. Traditional, state-of-the-art and future thermal building insulation materials and solutions - Properties, requirements and possibilities, Energy and Buildings 43(10): 2549-2563. https://doi.org/10.1016/j.enbuild.2011.05.015

Ji, J.; Li, Y. F.; Shi, W. X.; Sun, J. H. 2015. Numerical studies on smoke spread in the cavity of a double-skin façade, Journal of Civil Engineering and Management 22(4): 470-479. https://doi.org/10.3846/13923730.2014.897992

Jiang, L.; Xiao, H.; Zhou, Y.; An, W.; Yan, W.; He, J.; Sun, J. 2013. Theoretical and experimental study of width effects on horizontal flame spread over extruded and expanded polystyrene foam surfaces, Journal of Fire Sciences 32(3): 193-209. https://doi.org/10.1177/0734904113505677

Jiang, L.; Xiao, H.; An, W.; Zhou, Y.; Sun, J. 2014. Correlation study between flammability and the width of organic thermal insulation materials for building exterior walls, Energy and Buildings 82: 243-249. https://doi.org/10.101 6/j.enbuild.2014.06.013

Papadopoulos, A. M. 2005. State of the art in thermal insulation materials and aims for future developments, Energy and Buildings 37(1): 77-86. https://doi.org/10.1016/j.enbuild.2004.05.006 
Quintiere, J. G. 2001. The effects of angular orientation on flame spread over thin materials, Fire Safety Journal 36(3): 291312. https://doi.org/10.1016/S0379-7112(00)00051-5

Quintiere, J. G. 2006. Fundamentals of fire phenomena. John Wiley \& Sons, UK. https://doi.org/10.1002/0470091150

Ruzgys, A.; Volvačiovas, R.; Ignatavičius, Č.; Turskis, Z. 2014. Integrated evaluation of external wall insulation in residential buildings using SWARA-TODIM MCDM method, Journal of Civil Engineering and Management 20(1): 103-110. https://doi.org/10.3846/13923730.2013.843585

Stec, A. A.; Hull, T. R. 2011. Assessment of the fire toxicity of building insulation materials, Energy and Buildings 43(23): 498-506. https://doi.org/10.1016/j.enbuild.2010.10.015

Tsai, K.-C. 2007. Upward flame spread on a flat surface, in a corner and between two parallel surfaces, Journal of the Chinese Society of Mechanical Engineers 28(3): 341-348.

Tsai, K.-C. 2009. Width effect on upward flame spread, Fire Safety Journal 44(7): 962-967. https://doi.org/10.1016/j. firesaf.2009.06.003

Tsai, K.-C. 2011. Influence of sidewalls on width effects of upward flame spread, Fire Safety Journal 46(5): 294-304. https://doi.org/10.1016/j.firesaf.2011.03.006

Yan, W.; Shen, Y.; An, W.; Jiang, L.; Sun, J. 2015a. Experimental study on fire risk of buildings' U-shaped exterior wall on flame propagation of insulation material on plain and plateau, Journal of Fire Sciences 33(5): 358-373. https://doi.org/10.1177/0734904115596181

Yan, W.; Shen, Y.; Jiang, L.; An, W.; Zhou, Y.; Li, Z.; Sun, J. 2015b. Experimental study of sidewall and pressure effect on vertical downward flame spread over insulation material, in The $10^{\text {th }}$ Asia-Oceania Symposium on Fire Science and Technology, 2015, Tsukuba, Japan.

Yan, W.; Wang, C.; Guo, J. 2012. One extended OTSU flame image recognition method using RGBL and stripe segmentation, in D. Sun, W. P. Sung, R. Chen (Eds.). Applied mechanics and materials, Vols. 121-126: 2141-2145.

Zhang, Y.; Huang, X.; Wang, Q.; Ji, J.; Sun, J.; Yin, Y. 2011. Experimental study on the characteristics of horizontal flame spread over XPS surface on plateau, Journal of Hazardous Materials 189(1-2): 34-39. https://doi.org/10.1016/j. jhazmat.2011.01.101

Zhang, Y.; Sun, J. H.; Huang, X. J.; Chen, X. F. 2013. Heat transfer mechanisms in horizontal flame spread over wood and extruded polystyrene surfaces, International Journal of Heat and Mass Transfer 61: 28-34. https://doi.org/10.1016/j.ijheatmasstransfer.2013.01.069

Weigang YAN. He is a PhD graduated from the State Key Laboratory of Fire Science, University of Science and Technology of China and now a researcher in University of Shanghai for Science and Technology.. His main research interest is flame spread over insulation materials.

Lin JIANG. He is a PhD student of the State Key Laboratory of Fire Science, University of Science and Technology of China from September 2012.

Weiguang AN. He is a PhD graduated from the State Key Laboratory of Fire Science, University of Science and Technology of China and now a researcher in China University of Mining and Technology.

Yang ZHOU. He is a PhD graduated from the State Key Laboratory of Fire Science, University of Science and Technology of China and now a researcher in Central South University.

Jinhua SUN. He is a professor in the State Key Laboratory of Fire Science, University of Science and Technology of China. He is also the leading scientist of the National Basic Research Program of China (973 Program, grant no.2012CB719702). 